\title{
Green in the heart or greens in the wallet? The spatial uptake of small-scale renewable technologies
}

\author{
Grant J. Allan * \\ $\&$ \\ Stuart G. McIntyre ${ }^{\dagger}$
}

\begin{abstract}
The introduction of a Feed-in-Tariff (FIT) support mechanism has spurred development of small-scale domestic renewable electricity generation throughout Great Britain (GB), however the spatial pattern of uptake has been been uneven, suggesting that local, as well as between neighbourhood factors may be at important. As well as confirming that local socio-economic factors, including wealth, housing type and population density are found to be important in explaining uptake of this policy, local "green" attitudes - measured in three different ways - are shown not to be important. Existing local technical expertise, proxied for using data on smallscale renewable electricity devices in each area prior to the introduction of FIT, is an important factor in explaining subsequent adoption. Critically, we also find that there are spatial (i.e. between neighbourhood) processes explaining the uptake of these technologies. Taken together, our results suggest that, as currently designed, FIT policy may be regressive in income and could exacerbate spatial economic inequalities.
\end{abstract}

Keywords: Solar Energy, Feed-in Tariffs, Environmental Sentiment, Spatial Econometrics

JEL: R11, H23, Q42

\footnotetext{
${ }^{*}$ Corresponding author. Address: Department of Economics, University of Strathclyde, Sir William Duncan Building, 130 Rottenrow, Glasgow G4 0GE, Scotland, UK; Phone: +44 (0) 141548 3838, grant.j.allan@strath.ac.uk

${ }^{\dagger}$ Department of Economics, University of Strathclyde, Sir William Duncan Building, 130 Rottenrow, Glasgow G4 0GE, Scotland, UK; Phone: +44 (0)141 548 3858, s.mcintyre@strath.ac.uk
} 


\section{Introduction}

In order to meet their environmental goals, governments are turning to economic instruments (e.g. taxes/subsidies) to encourage the adoption of renewable energy technologies, including by households. A Feed-in Tariff (FIT) - which guarantees a price for electricity generated from renewable technologies - is one such instrument and have been introduced in, among other countries, the UK, Germany and Japan in recent years, and FITs are now being introduced in the USA ${ }^{1}$ (Muhammad-Sukki et al. 2014; Campoccia et al. 2014). In April 2010, a FIT was introduced for small-scale renewable electricity technologies in Great Britain. This promised the installing household a fixed price per unit of electricity and has spurred significant development of, particularly, domestic photovoltaic (PV) installations ${ }^{2}$.

To ensure the success of these policies, as well as to anticipate its wider impacts on society, it is important to understand the factors that help to explain the adoption of these technologies by households. The UK Government undertook an assessment of uptake of the FIT in its first twenty-one months of operation, i.e. from April 2010 to the end of 2011, and examined correlations between uptake and economic and socioeconomic features of local areas (Department of Energy and Climate Change, 2012). It found that greater levels of installation was correlated with greater wealth - an expected feature given that households are required to finance the upfront costs of installation a greater share of properties which were detached, higher housing values, and were also those areas with an older and more educated population. Similar factors have been identified in a number of other studies which have sought to assess correlations between economic and socio-economic features and renewable energy uptake of small-scale devices

\footnotetext{
${ }^{1}$ See: http://www.eia.gov/todayinenergy/detail.cfm?id=11471

${ }^{2}$ Between April 2010 and June 2012, over 1GW of domestic renewable electricity capacity was developed across 294,709 installations. For domestic installations, the most common technology was PV, contributing $99.5 \%$ of all installations and 98.7 percent of total capacity. As of March 2013, FITsaccredited installations produce almost $500 \mathrm{GWh}$ of electricity: roughly $0.5 \%$ of all domestic electricity consumption in Great Britain.
} 
(Bergman and Jardine (2009); Hawkes et al. (2011); Baskaran et al. (2013); Balcombe et al. (2013)).

In addition to economic and socio-economic factors it has been argued that "potential adopters [of household renewable energy devices] are driven by the desire to show others their environmental commitment" (Balcombe et al., 2013, p. 664). This suggests two things that have been largely neglected in the literature to date: first, that environmental sentiment may be important in explaining the uptake of these devices and, second, the public visibility of these devices (with households' adoption public knowledge), as well as spatial differences in climate, suggests that spatial processes might play an important role in explaining the uptake of these devices. A small number of studies have recently begun to explore whether there are spatial processes in the uptake of solar renewable technologies. These have explored the scale of "peer" effects - i.e. a link between adoption and subsequent adoption within the same neighbourhood - in the US (Bollinger and Gillingham, 2012; Graziano and Gillingham, 2014) and UK (Richter, 2013). These studies however share a limitation in examining uptake within existing neighbourhoods, and ignore spillovers between neighbourhoods (Richter, 2013). A key contribution of this paper therefore is the explicit use of spatial econometric techniques to examine the role of between neighbourhood spatial processes in explaining the uptake of smallscale renewable energy devices. Specifically, we examine the installation of small-scale domestic solar (PV) devices in England in the two years following the introduction of FIT, i.e. between April 2010 and June 2012.

We address three critical factors for the uptake of such devices. First, we explore the "between area" spatial processes affecting deployment of small-scale solar capacity. For instance, our spatial focus allows us to examine if uptake in one area is affected by adoption in neighbouring areas. We can distinguish between local and global spatial spillovers (LeSage, 2014). In the former, while there are impacts of changes in one area (A) on a neighbouring area (B), there are no endogenous feedbacks back to the first 
area. In global spatial spillovers, these feedbacks propagate throughout the system. Following LeSage (2014) - given, as we argue later, that we believe that the process under consideration here is characterised by a global process - we estimate the Spatial Durban Model (SDM). By testing the statistical significance of the spatial parameters in the SDM model, we can test whether this general model, or one of its nested models, is the most appropriate to explain the uptake of renewable energy devices under FITs. Our results confirm the presence of such spatial processes underpinning the uptake of small-scale solar capacity in England in the period under examination.

Second, in line with the existing literature on the uptake of household renewable energy devices, we include a range of economic and socio-economic variables including income, housing wealth, age and qualification levels, and measures of existing expertise in each area. Third, we also test for the role played by environmental sentiment using three measures drawn from voting and household behaviours. While we find no relationship between environmental sentiment - on any of our measures - and the installation of renewable electricity devices by households under FITs, we do however confirm the expected relationship between many of the socio-economic and economic variables and PV uptake. In particular, household wealth is strongly associated with uptake. Together with our results for environmental sentiment, this suggests that it is financial ability rather than environmental willingness which underpins the uptake of solar devices in England under FITs.

Our article proceeds as follows; we begin by identifying the relevant literature on the uptake of small-scale renewable energy technologies, noting that spatial processes have typically been neglected to date. We then outline the FIT policy in Great Britain, then we describe the data used in this study and the econometric methods employed. We then present and discuss our results before providing brief conclusions. 


\section{Literature}

A small number of papers have examined the uptake of small scale renewable energy devices by households (Bergman and Jardine, 2009; Hawkes et al., 2011; Baskaran et al., 2013; Balcombe et al., 2013). A common theme in these studies is the importance of controlling for key socio-economic characteristics, e.g. income, housing wealth, etc. (Bergman and Jardine, 2009; Balcombe et al., 2013; Baskaran et al., 2013), as well as housing characteristics such as tenure (whether the property is owned or rented, for example) and property type (Hawkes et al., 2011; Balcombe et al., 2013). Further, Hawkes et al. (2011) shows that the availability of appropriately qualified installers affects local uptake.

Balcombe et al. (2013) examines consumers' adoption of micro-generation technologies in the UK, and conclude that the most significant barrier is capital costs. Balcombe et al. (2013) also show that the key factors affecting uptake include housing wealth, home ownership and the type of property. Bergman and Jardine (2009) looked at the uptake of domestic micro-generation under the Low Carbon Building Programme and demonstrates that significant spatial variation in the uptake of devices between areas still exists, even after controlling for a range of socio-economic and housing characteristics.

The appreciation of a possible spatial process to the uptake of solar devices is a recent phenomenon. Bollinger and Gillingham (2012) examine the uptake of PV in California and explore the scale of "peer effects". Likewise, Graziano and Gillingham (2014) consider the case of Connecticut. These studies use econometric panel data techniques and exploit local databases of PV uptake, including dates on installation and adoption, to explore the timing of investments in solar devices. Bollinger and Gillingham (2012) finds strong support for causal peer effects to adoption, with additional installations increasing the probability of subsequent adoptions in each neighbourhood. They suggest that the panels' visibility and "word of mouth" are the key routes through which peer 
effects propagate, a result also confirmed by Graziano and Gillingham (2014), who also find that these effects diminish with distance.

The first UK study - and the only to date - tests for the presence of such effects in the uptake of solar PV since the introduction of FIT in 2010 (Richter, 2013). Using a similar approach to the US studies (Bollinger and Gillingham, 2012; Graziano and Gillingham, 2014) this paper finds that one more solar PV installation in a postcode district increases the number of new adoptions by 0.0005. Although small, this argues - as does both Bollinger and Gillingham (2012) and Graziano and Gillingham (2014) do - that social effects working at the local level could be useful in promoting further adoption.

These studies demonstrate the existence of within neighbourhood effects, they focus on how changes in installations are affected by earlier installations in that same area. They neglect however, the possibility that there could be spillovers between areas, such that development in one area could impact on neighbouring areas, which could then impact on its own neighbouring areas ${ }^{3}$. This paper is the first, to the authors knowledge, to fill this research gap. To do so, we employ spatial econometric techniques to examine domestic small-scale PV installations in England to test for the presence, and scale, of between area effects in explaining the uptake.

\section{Feed-In Tariff policy}

There are three elements to the financial return to domestic owners of FIT-accredited small-scale renewable technologies ${ }^{4}$. First, owners receive a payment ("Generation tariff") from the local energy supplier for each unit (or kWh) generated. Generation tariffs are differentiated by technology and the scale of installed capacity and were initially

\footnotetext{
${ }^{3}$ Richter (2013) writes "The first major constraint of the model employed in this paper is that social effects are assumed to spread within predefined neighbourhoods only, while spillovers across the neighbourhood borders are ignored. Spatial econometric methods, for example, could be employed to allow for more diverse spatial effects".

${ }^{4}$ Installations must be smaller than 5MW to be accredited for the scheme. In the first three years of the policy, the average capacity per domestic installation has been between 3 and $4 \mathrm{~kW}$.
} 
guaranteed for up to 20 years $^{5}$. Second, users receive a payment $(3.30 \mathrm{p} / \mathrm{kWh}$ for PV installations during our sample) for surplus electricity exported to the grid (i.e. an "Export tariff" applies to electricity not used within the domestic property). Finally, users benefit from lower electricity bills from their reduced use of "imports" from the electricity grid. Importantly, appropriate installations made prior to April 2010 (i.e. before the introduction of FITs) were able to "transfer" to a generation tariff appropriate to both their domestically-installed technology and its capacity.

While households receive an income stream over the lifetime of the device under FIT, they must meet the upfront capital costs of installing the device themselves ${ }^{6}$. This is a change from the policy before FITs (i.e. pre-April 2010), under which limited grants were available to help meet the capital cost of installing renewable technologies at the domestic scale. This change in policy arguably makes it harder for lower income households to install one of these devices. In terms of the types of technology covered by FIT, most domestic renewable technologies qualify for the scheme although, as we shall see, uptake of FITs (both in number of installations and share of capacity) is dominated by solar PV:

- Solar (PV) (either roof mounted or stand alone)

- Wind turbines (building mounted or free standing)

- Hydroelectricity

- Micro combined heat and power (CHP)

- Anaerobic digesters

\footnotetext{
${ }^{5}$ For instance, for solar PV technologies with a Total Installed Capacity of $4 \mathrm{~kW}$ or less on new buildings the tariff in year one of the FIT (financial year 2010-11) was $40.83 \mathrm{p} / \mathrm{kWh}$.

${ }^{6}$ The upfront cost for a domestic PV system typically lies in the range of $£ 9000$ and $£ 13000$ (Cherrington et al., 2013; Muhammad-Sukki et al., 2013), and from a private (household) perspective, a return on investment of 9-10\% was typical for a domestic PV installation (Cherrington et al., 2013). It is worth noting that there have been significant cost reductions in PV technologies as the market for devices in the UK has expanded (Balcombe et al., 2013), which has had implications both for the level of capital required and the $\mathrm{PV}$ tariff levels.
} 
For domestic properties receiving FIT, generation payments to households - made by the local electricity supplier - are met from a tariff on electricity consumption - and so are received firstly by the same local supplier. Through a process called "levelisation" these costs are distributed across all electricity suppliers in line with their respective market size; a process administered by the Office of Gas and Electricity Markets (OFGEM). This ensures that electricity suppliers in areas distributing more FITs payments than the tariff on consumption they receive from households in that same area are compensated from other electricity suppliers. To give some idea of the scale of this policy, in the year to March 2013 payments of $£ 500$ million were made to FITs generators by electricity suppliers (OFGEM, 2013). In addition, the introduction of a 'Levy Control Framework', essentially a cap on the total amount of subsidy available to low carbon technologies in the UK and out of which funding for FIT comes, was partly stimulated by concern about the financial implications of the rapid uptake of FITs.

Table 1 shows the breakdown of the number and installed capacity by technology for domestic devices installed in England between April 2010 and June 2012. It is apparent that the most common form of technology is PV, with an average installed capacity of $3.45 \mathrm{~kW}$. Wind and hydro installations are, on average, larger in capacity terms but they constitute only $1.07 \%$ of total installed capacity and around $0.41 \%$ of all installations. One reason for this is likely to stem from the ease of installation and the relatively unobtrusive nature of these devices. Installation of wind turbines, for example, have tougher restrictions on where they can be installed. In addition, the costs of residential solar PV systems have decreased significantly in the past decade.

[Table 1 here]

Despite success in increasing the installation of household renewable devices, "a large disparity still exists between regions... over the total numbers installed" (OFGEM, 2013, p.17). The South West and South East of England regions have both seen over 50,000 installations - with $23.6 \%$ and $15.8 \%$ of total capacity (MW) - while London 
and the North East are each the location for fewer than 20,000 installations (with 2.5\% and $3.2 \%$ of total capacity respectively)(OFGEM, 2013). This regional, and inherently spatial, inequality is something that should be concerning to policymakers in the UK given that it reinforces existing spatial economic inequalities. This is a state subsidy for electricity generation (and hence consumption) and is being taken up the most by the most prosperous regions of the UK. Given enduring concerns about fuel poverty, for instance, and the high price paid by some of the most vulnerable electricity consumers in the UK, the current design of this policy appears to raise real equity concerns.

\section{Data}

Our main data source is the OFGEM database of all FITs accredited installations in Great Britain (GB). This provides the electricity technology, capacity, date of commissioning and postcode for individual installations. From this database we extract installations in domestic properties commissioned in England between April 2010 and June $2012^{7}$. We omit Scotland and Wales from our sample as all economic and socio-economic variables were only available on a consistent basis for England.

This database also provides information on installations accredited prior to April 2010, that have subsequently transferred onto receiving FITs payments. From Table 2, we identify that 4,494 of the 270,918 installations in our sample were first commissioned prior to April 2010. We aggregate our postcode level installation data to the local authority level, which seems appropriate as this is the level at which local planning and development policies are formulated. In total there are 326 local/district authorities in England. While many renewable installations are in fact 'permitted developments', and have been since before FITs came into effect, evidence from an industry survey of local

\footnotetext{
${ }^{7}$ We focus on the level of uptake of domestic PV over this period. Changes to the PV tariffs were made as uptake exceeded expectations, however these were fairly modest over this period. The timing of installations may in part reflect the changing financial incentives announced for future years, however by focusing only on the first twenty-six months of FIT we leave this point for future work.
} 
authorities in 2011 suggested that many (over $83 \%$ of Local Authorities who responded) incorrectly believed that planning permission was required for the installation of solar panels under FITs ${ }^{8}$. For these reasons we believe that the Local Authority level is the most appropriate level to analyse variation in the uptake rate of FITs.

[Table 2 here]

We include a range of variables to capture the socio-economic characteristics which would be expected to impact on domestic FITs uptake, and which are detailed in Table 3. This includes the ratio of flats to houses (areas with fewer roofs provide less physical infrastructure for PV developments), the employment rate (to capture household incomes from employment), the ratio of home outright ownership to mortgage ownership (with greater housing ownership suggesting greater household wealth ${ }^{9}$ ), and a measure of the education of the population.

[Table 3 here]

We include the local development of renewable technology prior to April 2010 as a proxy for existing technical capacity and expertise in an area. As introduced earlier, prior to the introduction of the FIT scheme households could apply for a grant to install such a device (thus helping defray the capital cost) but very few devices were actually installed. We would argue that the rate of installations prior to the introduction of the FiT policy is a good proxy for the local expertise in the installation of these devices at the time the policy came into place. More installations in an area pre-FiTs suggests greater expertise and experience among local companies in the installations of these devices and thus greater capacity to respond to the subsequent increase in demand from

\footnotetext{
${ }^{8}$ See http://www.renewableenergyinstaller.co.uk/wp-content/uploads/2011/11/REI_ Magazine_Issue $10 . p d f$

${ }^{9}$ Households with greater housing equity would also be able to borrow the cost of installing against their property. Note, to our knowledge, there are no restrictions on the installations of these devices in rental properties in the UK, although the 'incentive' would clearly be stronger for landlords where the electricity generated was attached to a smart meter and set to 'export' all generated electricity to the grid rather than be used by the tenants.
} 
households wishing to take advantage of the incentives offered by this policy. Further, since joining the FITs scheme was reasonably straightforward for technologies installed prior to the policy being introduced, and the scheme offered generous returns for electricity generated, we believe that we have a good representation of pre-FITs installation activity. It may also be the case that installations prior to the introduction of the FiTs scheme influenced subsequent adoption through the 'visibility' of these technologies to households, however the number of installations prior to the introduction of the FiT scheme was low (3,870 compared to 269,449 between the introduction of the scheme and the cut off point in our data (see Tables 1 and 2)) suggesting that there was not the kind of widespread visibility that would stimulate this kind of process.

Table 2 provides the technology mix of devices installed prior to the introduction of FITs which were subsequently accredited under this policy, again demonstrating the dominance of PV in the technology mix. Alternative measures based on Standard Industrial Classification (SIC) code employment or economic activity have, in contrast, proved infeasible as a measure of existing technological expertise in this area given the degree of sectoral aggregation inherent in SIC code data.

In addition, we are keen to explore whether differences in environmental (or 'green') sentiment between local authority areas can help explain variation in the uptake of this policy. With this in mind we explore three measures that might proxy for such sentiment. The first of these is a dummy variable indicating whether there was no UK Green Party candidate in the elections to the local authority election during the time period studied here. While this is admittedly a crude measure, given that the UK Green Party did not field candidates in all local authorities, it is reasonable to expect that they fielded candidates where they believed that they had the greatest probability of being elected and therefore where environmental sentiment was strongest.

That being said there are other dynamics involved in local elections, for instance tactical voting and incumbent advantage, which might lead those with environmental 
sentiments to vote for other parties/candidates and thus understate the support for the UK Green Party, leading the UK Green Party to not field candidates in local elections in that area. Therefore, we also utilise data on votes for the Green Party in the 2009 European Parliament election, which are recorded for each local authority. Votes are cast in European elections on a Proportional Representation (PR) basis, and PR elections greatly erode the incentives for voters to vote tactically, giving a better measure for the degree of environmentalism in each local authority area. Nevertheless, it could be argued that voting for the UK Green Party at elections is not the same as the expression of environmental sentiment given that election campaigns generally involve a broad range of issues. However, we would argue that the over-riding emphasis of the UK Green Party is its identification with environmental protection and 'green' issues, and therefore that this is a good proxy for environmentalism generally.

Nonetheless, in order to explore 'green' sentiment among the population further, free of the complications that arise in elections, we also utilise one further measure of environmentalism at a local level; the rate of recycling by households. In the UK, households are not paid to recycle domestic waste. Household waste is collected and processed by the local authority, at their expense, sometimes in concert with private contractors. Households pay for this waste collection service as part of their total council tax payment (and councils also receive money directly from central government to support their activities across all areas (education, social work, parks, waste collection, etc.). Given the absence of a financial incentive for households to recycle (or financial penalties for not recycling), the incentives for households to engage in this activity are non-pecuniary. This allows us to consider a broader measure of environmentally friendly behaviour as our measure of environmental sentiment. We use all three of our measures of environmental sentiment - the absence of a UK Green Party candidate; support for the UK Green Party in a PR election; and recycling rates - to determine whether these proxies for environmental sentiment help us explain the uptake of the PV devices. 
[Table 4 here]

In understanding the uptake of the FIT devices at domestic scale, we focus only on the most commonly adopted technology, PV, which Table 1 showed represented $99.46 \%$ of devices accredited under FITs during the period of our study. An obvious spatial factor to the uptake of these devices comes from variation in the solar irradiation. In order to capture this in our study we utilise a calculator of the performance of grid connected PV. The calculator, provided by the European Commission Joint Research Centre, provides estimates for particular locations of yearly averages of solar irradiance using GIS software $^{10}$. We used the calculator with geographic identifiers for each local authority area and estimated the solar irradiance based on a crystalline silicon cell technology. We use the 'Average sum of global irradiation per square meter received by the modules of the given system $\left(\mathrm{kWh} / \mathrm{m}^{2}\right)^{\prime}$ measure reported by this calculator in our study. Descriptive statistics for all variables considered in our study are presented in Table 4. Economic and socio-economic variables are typically taken from UK Neighbourhood Statistics website (neighbourhood.statistics.gov.uk).

\section{Modelling strategy}

Following LeSage (2014) we can think of there being two main spatial econometric models, within which other econometric models are nested. These two models are the spatial Durbin model (SDM) and the spatial Durbin error model (SDEM). A similar point is made by Elhorst $(2014,9)$, although he still includes the SAC model in his diagram which, as we will argue shortly, is unnecessary to specify as a separate model. The SDEM model is a local spillover model, capturing spillovers from one area to another area which do not embody endogenous feedback effects beyond their impacts on their immediate neighbours. In other words, the spillovers do not generate additional (endoge-

\footnotetext{
${ }^{10}$ The calculator is available at: http://re.jrc.ec.europa.eu/pvgis/apps4/pvest.php.
} 
nous) spillover effects. The SDM model however is a global spillover model, representing a process characterised by endogenous feedback effects.

A good example to illustrate what local and global spillovers are, and consequently what we mean by endogenous feedback effects, comes from the classic state cigarette tax case. We might observe a local spillover if smokers in one state shop for cigarettes in neighbouring states where cigarette taxes are lower; however we might not anticipate that this spillover would impact on the rate of state cigarette tax in neighbouring states. On the other hand, if the decision to change the cigarette tax in one state led to neighbouring states changing their cigarette taxes, which led to neighbours of those neighbouring states changing their cigarette taxes, etc., etc., then there would be endogenous feedback effects and a global spillover process.

Having explained the intuition behind these two types of models, embodying two different types of feedback effects, we will now formally outline the SDEM and SDM models. The SDEM model, where $y$ denotes the dependent variable, $X$ the matrix of covariates, and $W$ the spatial weight matrix (which, as is standard in spatial econometrics, is row normalised) takes the form:

$$
\begin{aligned}
& y=X \beta_{1}+W X \beta_{2}+u \\
& u=\rho W u+\epsilon \\
& \epsilon \sim N\left(0, \sigma_{e}^{2} I_{n}\right)
\end{aligned}
$$

The SDEM, if the spatial term $\rho$ is found to be insignificant, reduces to the spatial lag of X (SLX) model. Similarly, if $\beta_{2}$ is found to be insignificant the SDEM model reduces to the spatial error (SEM) model. Where both spatial terms are found to be insignificant the SDEM reduces to the classic linear regression model. Meanwhile, the SDM can be expressed as follows: 


$$
\begin{aligned}
& y=\rho W y+X \beta_{1}+W X \beta_{2}+\epsilon \\
& \epsilon \sim N\left(0, \sigma_{e}^{2} I_{n}\right)
\end{aligned}
$$

In the SDM model, if $\beta_{2}$ is found to be insignificant, it is straightforward to see that we are left with the spatial autoregressive (SAR) model. Similarly, the SLX model emerges where $\rho$ is found to be insignificant. LeSage and Pace $(2009,31)$ show that a commonly considered spatial econometric model, the SAC model, contains elements of both the SAR and SEM models and that a linear combination of the SAR and SEM models implies the SDM model. LeSage (2014) argues that this confusion arises because of the intuitive appeal of the SAC model in representing spatial dependence in the dependent variable and a spatial dependence in the error term; this is clear if one presents the SAC model formally:

$$
\begin{aligned}
& y=\rho W y+X \beta_{1}+u \\
& u=\lambda W u+\epsilon \\
& \epsilon \sim N\left(0, \sigma_{e}^{2} I_{n}\right)
\end{aligned}
$$

LeSage (2014) argues that global spillover phenomena are likely to be fairly rare, and that in applied work, "most spatial spillovers are local" (LeSage, 2014, 3). However, we focus on estimating the SDM model, representing a global spillover process. The reason for this is that we believe that the process we are trying to understand, the local level uptake of household renewable energy devices under the feed-in-tariff policy, is one characterised by endogenous feedback effects. We believe that the spatial dimension to this problem is not limited to a local phenomenon. 
Specifically, we would argue that the rate of uptake of these devices is driven by both household knowledge and the availability of technical expertise. One of the key challenges in fostering household uptake of energy policy initiatives is increasing public knowledge and getting the attention of the public ${ }^{11}$. Given the public nature of the installation of household solar panels in the community, adoption by households in one area will increase awareness among the broader community. Widespread adoption in one community will be noticed by neighbouring communities, which may foster adoption in those neighbouring communities, and through the same process impact areas neighbouring them.

In addition, uptake of these devices in an area will likely also mean that neighbouring areas benefit from shared technical installation expertise. Uptake of household renewable energy devices in an area will create demand for local technical expertise in the installation of these devices, but, as increasing adoption in that area reduces new installation opportunities, installation companies will need to seek fresh installation opportunities in neighbouring areas. In this sense, one may consider that the capitalist motives of the installers result in supply creating its own demand as installers seek out new customers. This is a second route through which one would expect spillovers in the adoption of household renewable energy devices. As outlined earlier, the nature of the spatial process, and indeed the presence of a spatial dimension to this problem, can be tested empirically by assessing the statistical significance of the key spatial parameters in Equation 3 above.

We therefore estimate a Bayesian SDM model with proper but relatively uninformative priors in all cases. The Gibbs sampler was run for 200,000 draws with a 'burn-in' of 20,000 draws. Our model includes a heteroskedasticity correction in the calculation of the standard errors. Our spatial weight matrix is specified on the basis of contigu-

\footnotetext{
${ }^{11}$ Increasing public awareness is a recurring theme of many energy policy commentaries such as those produced by the International Energy Agency, see for instance: https://www.iea.org/publications/ freepublications/publication/Energy_Policy_Highlights_2013.pdf
} 
ity. LeSage (2014) demonstrate that the precise specification of the weight matrix, for instance contiguity, n-nearest neighbour etc, makes little difference to the results of a well specified spatial econometric model provided that the correct marginal effects are calculated. Following LeSage and Pace (2009) we calculate the proper marginal effects estimates for a spatial econometrics model with a lagged dependent variable, such as the SDM model. This means that we calculate and report the direct, indirect and total effects estimates for all covariates. The direct effect is the impact of each covariate in that area on the dependent variable in that area, the indirect effect is the impact of each covariate on the dependent variable in neighbouring areas, while the total effect is the sum of the direct and indirect effects.

\section{Results}

The SDM model is run separately with the results from using each of the three measures of environmental sentiment described above, presented in Tables 5-7. The SDM model, as discussed earlier, is the most appropriate model to estimate when one believes that there is a global spillover process involved. In addition, this model captures the impact of any omitted variables that follow a spatial process and are correlated with included variables, meaning that we can be confident that our results are robust to omitted variables. In line with standard practice in Bayesian estimation we calculate credible intervals (at both 95\% and 99\%) for our estimates. Where the upper and lower credible intervals do not include zero the coefficient can be considered statistically significant at the $95 \%$ level.

[Table 5-7 here]

First, we can see that in all of our results in Tables 5-7 the spatial coefficient $(\rho)$ is significant (i.e. the credible interval does not include zero), indicating the importance of modelling FIT uptake using spatial econometric methods. In addition it demonstrates 
that the SDM model and not the SLX model is the appropriate model in our case. Intuitively, what this means is that the rate of uptake of household renewable energy devices by households in the UK is not independent of the rate of uptake in neighbouring areas. Given that one of the key factors in the impacts of household energy policy interventions is visibility and public awareness, this is perhaps to be expected, albeit still needing to be statistically demonstrated.

Second, we turn to the socio-economic variables. The ratio of flats to houses is, as expected, negative in all cases (and statistically significant at the $1 \%$ level) indicating that the greater the ratio of flats to houses the lower the uptake of solar PV devices. There are no restrictions on the installation of solar panels on flat dwellings, however there are some important practical considerations (the available roof space per dwelling is lower, and there are coordination problems associated with multi-household properties). We similarly find, in all cases, that population density is negative and significantly associated with the uptake of devices under FITs at the $1 \%$ level.

The ratio of homes owned outright to those owned with a mortgage is found to be positive and significant at the $1 \%$ level in all cases. This suggests that areas with greater housing equity are associated with greater uptake of these devices. Given the way the policy is structured this makes sense - the requirement for households to fund the upfront cost of installation makes adoption by households with greater housing equity, among other characteristics, more likely. In concert with the way this policy is financed, through a spatially blind levy on electricity consumption, this raises questions about whether this policy will create or exacerbate economic inequalities between areas of the UK.

We included a measure of solar irradiation in our models to see whether variation in the level of solar irradiation between each area could help explain differences in the uptake of these devices. Our results show that in none of our models is our solar irradiance variable significant. While this result may seem surprising, it may simply 
be the case that there is not sufficient variation across the UK in solar irradiance to explain variation in the uptake of these devices. The UK occupies but a small part of the world. If this study was pan-European or focussed on the USA, this result may no longer hold. Our measure of local economic activity, the employment rate, is not significantly associated with the uptake of renewable energy devices under FITs in any of the models.

Our education variable - the proportion of the population with no formal qualifications - is negatively associated with the uptake of these devices in two of our three models. In the two models where our education variable is significant, it suggests that the greater the proportion of the population with no formal qualifications, the lower the uptake of these devices. The one model where our education variable is not significant is where we proxy for environmental sentiment using recycling rates. Since this is the most blunt proxy for environmentalism which we consider, it is perhaps not a surprise that the inclusion of this variable leads to our education variable becoming insignificant since it is likely to be picking up some of the same effect.

Third, in all areas there is a positive association at the $1 \%$ level between the uptake of these technologies in an area prior to April 2010 and subsequent installations of devices in that area. This suggests that existing technical capacity - e.g. local industrial and installation capabilities, local planning experience, etc - are important in explaining the pattern of installations under FITs. While it is not possible in our analysis to separate out the industrial or institutional factors, the presence of a significant effect here is important for policy design as it suggests that "initial conditions" do matter for subsequent adoption.

Fourth, we measure environmental sentiments in three different ways as outlined earlier. If the uptake of these devices was driven by environmental sentiment we would expect these variables to be positively associated with uptake of these devices. The first model (Table 5) proxies for environmentalism using a dummy variable to indicate the 
absence of a Green Party candidate in local elections. Using this measure the direct effect is insignificant, while the indirect and total effects are negative and significant (suggesting that the absence of a Green Party candidates in one area is associated with lower uptake of household renewable energy devices in neighbouring areas). Given that this variable is very broad in nature, and since the direct effect is insignificant, we are cautious about taking this to be evidence of any local green sentiment driving the uptake of household renewable energy devices.

Using our second proxy for environmentalism - the \% of the votes cast for the Green Party in the PR European Parliament elections - we can see (Table 6) that none of the effects estimates for this variable are significant. Given, as discussed earlier, that European Parliament elections are elected on a proportional representation basis where the incentive to vote tactically is greatly reduced, this is a better measure of the degree of support for environmental issues in the community. While elections generally revolve around a range of issues, the Green Party in the UK is predominantly associated with a platform on environmental issues and as such we believe that this is a reasonable proxy for local environmentalism.

That being said, for further robustness, we also considered a third measure of environmentally friendly behaviour: the share of household waste that is recycled in each Local Authority area. In the UK, households do not get paid to recycle nor is their household waste charge a function of the amount that they recycle. In this way, local recycling rates are explained by the behaviour of (democratically elected) local authorities and households locally, which we would argue give us a good proxy for variations between local authorities in relation to their environmental sentiment. In Table 7 we present our results from this third model. We can see that there is again no significant relationship between our measure of local environmental sentiment and the rate of uptake of household renewable energy devices in that area. Thus, robust across all three measures of environmental attitudes, we can find little evidence that local environmental 
sentiment explains the rate of uptake of solar devices by households. Installation of such devices seems to be a financial and not an environmental consideration.

\section{Conclusion and Policy Implications}

This article has sought to understand some of the factors affecting the development of "domestic" scale PV in England under the Feed-in Tariff (FIT) policy between April 2010 and June 2012. We make a number of important findings. Firstly, and in response to earlier questions in the literature on this point, we find that the uptake of this policy by households should be modelled using spatial econometric methods. Future econometric work in this area should therefore incorporate this spatial dimension into the modelling framework. In addition, we can see from examination of the indirect effects that the between area effects are important here, as was previously queried in the literature.

Next, we show that housing wealth, property type and the uptake of these devices prior to the introduction of FIT are important in understanding the subsequent uptake of FITs in an area, while other control variables (such as population density and housing type) accord with our expectations, and the recent literature. Finally, we provide no support for the view that the adoption of household renewable devices is driven by environmental or "green" sentiment, but instead seems to be driven by financial motives and opportunity; particularly wealth and housing characteristics.

Under FITs, all electricity consumers contribute to meeting the costs but not all consumers are equally capable of benefiting (e.g. because of the need to meet the upfront cost of installing a recognised device). As there are also spatial differences in the uptake of this policy between regions, significant inter-regional transfers are implied under this policy. In light of our findings in this article, and the design of FITs, this policy may be exacerbating existing interregional inequalities in Great Britain; something which is deserving of further analysis. 
Future work will extend the analysis in this article in a number of ways. Firstly, by analysing the "transfers" between areas implicit in the uneven pattern of FITs development across regions, combined with the levelisation of the costs across all consumers. Secondly, by examining how changes in the tariffs for PV technologies (MuhammadSukki et al., 2013) and technology cost reductions (Balcombe et al., 2013), have affected the temporal uptake and spatial distribution of domestic renewable energy developments. 


\section{Acknowledgements}

The authors are very grateful for the helpful comments of two anonymous referees. Grant Allan acknowledges funding from ClimateXChange, the Scottish Governmentfunded Centre of Expertise in Climate Change. The views expressed here are the sole responsibility of the authors, and are not necessarily those of ClimateXChange or the Scottish Government. 
Table 1: Renewable devices commissioned between April 2010 and June 2012, by technology type

\begin{tabular}{lrrrrr} 
Technology type & $\begin{array}{r}\text { Number of } \\
\text { installa- } \\
\text { tions }\end{array}$ & $\begin{array}{r}\text { \% of in- } \\
\text { stallations }\end{array}$ & $\begin{array}{r}\text { Installed } \\
\text { Capacity (kW) }\end{array}$ & $\begin{array}{r}\% \text { of } \\
\text { installed } \\
\text { capacity }\end{array}$ & $\begin{array}{r}\text { Average } \\
\text { Installed } \\
\text { Capacity } \\
(\mathrm{kW})\end{array}$ \\
\hline Photovoltaic (PV) & 269,449 & $99.46 \%$ & $929,527.51$ & $98.73 \%$ & 3.45 \\
Wind & 1081 & $0.40 \%$ & 9736.62 & $1.03 \%$ & 9.01 \\
Hydro & 33 & $0.01 \%$ & 410.43 & $0.04 \%$ & 12.44 \\
Micro CHP & 354 & $0.13 \%$ & 359.32 & $0.04 \%$ & 1.02 \\
Anaerobic digestion & 1 & $0.00 \%$ & $1,415.00$ & $0.15 \%$ & $1,415.00$ \\
Total & 270,918 & $100.00 \%$ & $941,448.88$ & $100.00 \%$ & - \\
\hline
\end{tabular}

Table 2: Renewable devices commissioned before April 2010 and subsequently transferred to FITs, by technology type

\begin{tabular}{|c|c|c|c|c|c|}
\hline Technology type & $\begin{array}{l}\text { Number of } \\
\text { installations }\end{array}$ & $\begin{array}{r}\% \text { of } \\
\text { installations }\end{array}$ & $\begin{array}{r}\text { Installed } \\
\text { Capacity } \\
(\mathrm{kW})\end{array}$ & $\begin{array}{r}\% \text { of } \\
\text { installed } \\
\text { capacity }\end{array}$ & $\begin{array}{r}\text { Average } \\
\text { Installed } \\
\text { Capacity } \\
(\mathrm{kW})\end{array}$ \\
\hline Photovoltaic & 3,870 & $86.11 \%$ & $11,313.70$ & $64.09 \%$ & 2.79 \\
\hline Wind & 550 & $12.24 \%$ & $4,448.80$ & $23.98 \%$ & 7.36 \\
\hline Hydro & 73 & $1.62 \%$ & $1,325.19$ & $5.41 \%$ & 12.51 \\
\hline Micro $\mathrm{CHP}^{12}$ & - & $0.00 \%$ & - & $0.00 \%$ & - \\
\hline Anaerobic digestion & 1 & $0.02 \%$ & $1,100.00$ & $6.52 \%$ & $1,100.00$ \\
\hline Total & 4494 & $100.00 \%$ & $18,187.69$ & $100.00 \%$ & - \\
\hline
\end{tabular}


Table 3: Variable definitions

\begin{tabular}{|c|c|c|c|}
\hline Variable & Definition & Source & Period \\
\hline Installs & Number of new domestic installations & OFGEM & April 2010 to June 2012 \\
\hline InstallCap & Capacity of new domestic installations & OFGEM & April 2010 to June 2012 \\
\hline EmpRate & $\begin{array}{l}\% \text { of population aged } 16-64 \text { in employ- } \\
\text { ment }\end{array}$ & Neighbourhood Statistics & 2010 \\
\hline NoQualRate & $\begin{array}{l}\% \text { of usual resident population aged } \\
\text { over } 16 \text { with no qualifications }\end{array}$ & Neighbourhood Statistics & 2011 \\
\hline OwnedToMortgage & $\begin{array}{l}\text { Ratio of number of houses owned out- } \\
\text { right to number with mortgage }\end{array}$ & Neighbourhood Statistics & 2011 \\
\hline PreFITs & $\begin{array}{l}\text { Number of domestic installations trans- } \\
\text { ferred to FITs }\end{array}$ & OFGEM & April 2010 to June 2012 \\
\hline PreFITsCap & $\begin{array}{l}\text { Capacity of domestic installations } \\
\text { transferred to FITs }\end{array}$ & OFGEM & April 2010 to June 2012 \\
\hline FlatsToHouses & $\begin{array}{l}\text { Ratio of "Flats, maisonette or apart- } \\
\text { ments" to "Whole house or bungalow" }\end{array}$ & Neighbourhood Statistics & 2011 \\
\hline PopDensity & All usual residents per hectare & Neighbourhood Statistics & 2011 \\
\hline $\begin{array}{l}\text { No Local Green Party } \\
\text { Candidate }\end{array}$ & $\begin{array}{l}\text { Dummy variable indicating the absence } \\
\text { of UK Green Party candidates in local } \\
\text { elections }\end{array}$ & Various & $\begin{array}{l}2010 \text { or nearest election } \\
\text { year }\end{array}$ \\
\hline Household recycling rate & $\begin{array}{l}\text { Household recycling contains materi- } \\
\text { als sent for recycling, composting or } \\
\text { reuse by local authorities as well as } \\
\text { those collected from household sources } \\
\text { by private/ voluntary organisations. }\end{array}$ & WasteDataFlow.org & 2012 \\
\hline GreenVote & $\begin{array}{l}\% \text { of vote for Green party candidate in } \\
2009 \text { European elections }\end{array}$ & $\begin{array}{l}\text { UK Parliament, House of } \\
\text { Commons Research Paper } \\
2009 / 53\end{array}$ & 2009 \\
\hline
\end{tabular}


Table 4: Descriptive statistics

\begin{tabular}{lrrrr} 
Variable & Max & Min & Mean & St. Dev \\
& & & & \\
\hline Number of PV Installations per HH & 0.08 & 0.00 & 0.01 & 0.01 \\
Employment rate & 0.87 & 0.00 & 0.72 & 0.07 \\
Ratio of Flats to Houses & 43.57 & 0.04 & 0.48 & 2.52 \\
Ratio of owned to mortgaged homes & 3.16 & 0.50 & 0.99 & 0.28 \\
\% pop with no qualifications & 0.35 & 0.07 & 0.22 & 0.05 \\
Population Density & 138.70 & 0.20 & 16.50 & 23.59 \\
Pre 2010 PV Installations per HH & 0.00 & 0.00 & 0.00 & 0.00 \\
Pre 2010 PV Installed Capacity per HH & 0.01 & 0.00 & 0.00 & 0.00 \\
\% Vote Green & 0.31 & 0.04 & 0.09 & 0.04 \\
Solar Radiation & 1490 & 1060 & 1263.77 & 78.19 \\
No Green Party local candidate & 1.00 & 0.00 & 0.26 & 0.44 \\
Household recycling rate & 0.67 & 0.12 & 0.42 & 0.10 \\
& & & & \\
\hline
\end{tabular}


Table 5: PV uptake under FITs \#1, England

\begin{tabular}{|c|c|c|c|c|c|}
\hline Direct & Lower $1 \%$ & Lower $5 \%$ & Mean & Upper $95 \%$ & Upper $99 \%$ \\
\hline Employment rate & -0.049 & -0.021 & 0.063 & 0.144 & 0.170 \\
\hline Flat to house ratio & -0.339 & -0.301 & -0.214 & -0.129 & -0.093 \\
\hline Owned-mortgage ratio & 0.154 & 0.180 & 0.261 & 0.344 & 0.371 \\
\hline Per. No qualifications & -0.210 & -0.183 & -0.097 & -0.011 & 0.017 \\
\hline Pop. Density & -0.479 & -0.441 & -0.322 & -0.201 & -0.163 \\
\hline Pre 2010 PV capacity & 0.098 & 0.131 & 0.240 & 0.356 & 0.394 \\
\hline Solar Irradiation & -0.141 & -0.106 & 0.005 & 0.118 & 0.154 \\
\hline No Green Party candidate & -0.207 & -0.169 & -0.047 & 0.077 & 0.116 \\
\hline Indirect & Lower $1 \%$ & Lower $5 \%$ & Mean & Upper $95 \%$ & Upper $99 \%$ \\
\hline Employment rate & -0.202 & -0.123 & 0.124 & 0.382 & 0.469 \\
\hline Flat to house ratio & -0.042 & 0.036 & 0.281 & 0.554 & 0.652 \\
\hline Owned-mortgage ratio & -0.224 & -0.161 & 0.044 & 0.260 & 0.337 \\
\hline Per. No qualifications & -0.060 & 0.008 & 0.228 & 0.456 & 0.535 \\
\hline Pop. Density & -0.430 & -0.332 & -0.069 & 0.174 & 0.248 \\
\hline Pre 2010 PV capacity & -0.099 & -0.014 & 0.272 & 0.585 & 0.697 \\
\hline Solar Irradiation & -0.143 & -0.092 & 0.059 & 0.212 & 0.264 \\
\hline No Green Party candidate & -0.665 & -0.575 & -0.312 & -0.061 & 0.018 \\
\hline Total & Lower $1 \%$ & Lower $5 \%$ & Mean & Upper $95 \%$ & Upper $99 \%$ \\
\hline Employment rate & -0.176 & -0.088 & 0.187 & 0.472 & 0.570 \\
\hline Flat to house ratio & -0.296 & -0.208 & 0.067 & 0.368 & 0.477 \\
\hline Owned-mortgage ratio & 0.041 & 0.103 & 0.305 & 0.522 & 0.600 \\
\hline Per. No qualifications & -0.160 & -0.089 & 0.131 & 0.363 & 0.444 \\
\hline Pop. Density & -0.766 & -0.664 & -0.391 & -0.142 & -0.068 \\
\hline Pre 2010 PV capacity & 0.107 & 0.199 & 0.512 & 0.857 & 0.979 \\
\hline Solar Irradiation & -0.087 & -0.049 & 0.064 & 0.181 & 0.221 \\
\hline No Green Party candidate & -0.728 & -0.632 & -0.359 & -0.105 & -0.026 \\
\hline
\end{tabular}

Lower 1\% Lower 5\% Mean Upper 95\% Upper 99\%
Rho
$0.233 \quad 0.361$
0.484

R-bar

0.484 
Table 6: PV uptake under FITs \#3, England

\begin{tabular}{|c|c|c|c|c|c|}
\hline Direct & Lower $1 \%$ & Lower $5 \%$ & Mean & Upper $95 \%$ & Upper $99 \%$ \\
\hline Employment rate & -0.060 & -0.027 & 0.066 & 0.154 & 0.180 \\
\hline Flat to house ratio & -0.363 & -0.327 & -0.233 & -0.138 & -0.093 \\
\hline Owned-mortgage ratio & 0.145 & 0.171 & 0.256 & 0.344 & 0.372 \\
\hline Per. No qualifications & -0.224 & -0.194 & -0.100 & -0.007 & 0.022 \\
\hline Pop. Density & -0.470 & -0.430 & -0.307 & -0.182 & -0.141 \\
\hline Pre 2010 PV capacity & 0.112 & 0.148 & 0.267 & 0.394 & 0.437 \\
\hline Solar Irradiation & -0.141 & -0.106 & 0.008 & 0.122 & 0.159 \\
\hline Per. Green Party votes & -0.101 & -0.081 & -0.017 & 0.050 & 0.072 \\
\hline Indirect & Lower $1 \%$ & Lower $5 \%$ & Mean & Upper $95 \%$ & Upper $99 \%$ \\
\hline Employment rate & -0.164 & -0.085 & 0.168 & 0.432 & 0.522 \\
\hline Flat to house ratio & -0.080 & 0.000 & 0.251 & 0.527 & 0.631 \\
\hline Owned-mortgage ratio & -0.246 & -0.181 & 0.028 & 0.248 & 0.326 \\
\hline Per. No qualifications & -0.020 & 0.049 & 0.278 & 0.517 & 0.599 \\
\hline Pop. Density & -0.350 & -0.256 & 0.010 & 0.259 & 0.338 \\
\hline Pre 2010 PV capacity & -0.041 & 0.044 & 0.337 & 0.662 & 0.784 \\
\hline Solar Irradiation & -0.151 & -0.102 & 0.054 & 0.211 & 0.263 \\
\hline Per. Green Party votes & -0.264 & -0.204 & -0.020 & 0.166 & 0.227 \\
\hline Total & Lower $1 \%$ & Lower $5 \%$ & Mean & Upper $95 \%$ & Upper $99 \%$ \\
\hline Employment rate & -0.143 & -0.050 & 0.235 & 0.529 & 0.627 \\
\hline Flat to house ratio & -0.350 & -0.262 & 0.018 & 0.325 & 0.438 \\
\hline Owned-mortgage ratio & 0.017 & 0.081 & 0.284 & 0.502 & 0.583 \\
\hline Per. No qualifications & -0.118 & -0.048 & 0.178 & 0.416 & 0.500 \\
\hline Pop. Density & -0.669 & -0.570 & -0.297 & -0.043 & 0.033 \\
\hline Pre 2010 PV capacity & 0.186 & 0.281 & 0.604 & 0.962 & 1.094 \\
\hline Solar Irradiation & -0.092 & -0.054 & 0.062 & 0.182 & 0.223 \\
\hline Per. Green Party votes & -0.295 & -0.231 & -0.036 & 0.160 & 0.227 \\
\hline
\end{tabular}

Lower 1\% Lower 5\% Mean Upper 95\% Upper $99 \%$
Rho
$0.229 \quad 0.359$
0.485

R-bar

0.492 
Table 7: PV uptake under FITs \#2, England

\begin{tabular}{|c|c|c|c|c|c|}
\hline Direct & Lower $1 \%$ & Lower $5 \%$ & Mean & Upper $95 \%$ & Upper $99 \%$ \\
\hline Employment rate & -0.046 & -0.015 & 0.074 & 0.159 & 0.186 \\
\hline Flat to house ratio & -0.349 & -0.314 & -0.227 & -0.137 & -0.092 \\
\hline Owned-mortgage ratio & 0.148 & 0.175 & 0.259 & 0.345 & 0.375 \\
\hline Per. No qualifications & -0.202 & -0.173 & -0.083 & 0.006 & 0.034 \\
\hline Pop. Density & -0.457 & -0.418 & -0.292 & -0.164 & -0.123 \\
\hline Pre 2010 PV capacity & 0.120 & 0.155 & 0.270 & 0.390 & 0.429 \\
\hline Solar Irradiation & -0.141 & -0.104 & 0.010 & 0.124 & 0.162 \\
\hline Per. HH waste recycled & -0.063 & -0.043 & 0.019 & 0.082 & 0.103 \\
\hline Indirect & Lower $1 \%$ & Lower $5 \%$ & Mean & Upper $95 \%$ & Upper $99 \%$ \\
\hline Employment rate & -0.156 & -0.076 & 0.180 & 0.450 & 0.544 \\
\hline Flat to house ratio & -0.099 & -0.021 & 0.231 & 0.507 & 0.608 \\
\hline Owned-mortgage ratio & -0.262 & -0.196 & 0.015 & 0.239 & 0.315 \\
\hline Per. No qualifications & -0.046 & 0.026 & 0.253 & 0.489 & 0.569 \\
\hline Pop. Density & -0.418 & -0.321 & -0.055 & 0.193 & 0.270 \\
\hline Pre 2010 PV capacity & -0.044 & 0.040 & 0.332 & 0.660 & 0.782 \\
\hline Solar Irradiation & -0.168 & -0.117 & 0.041 & 0.200 & 0.254 \\
\hline Per. HH waste recycled & -0.393 & -0.328 & -0.137 & 0.047 & 0.108 \\
\hline Total & Lower $1 \%$ & Lower $5 \%$ & Mean & Upper $95 \%$ & Upper $99 \%$ \\
\hline Employment rate & -0.124 & -0.034 & 0.255 & 0.556 & 0.660 \\
\hline Flat to house ratio & -0.361 & -0.273 & 0.004 & 0.307 & 0.419 \\
\hline Owned-mortgage ratio & 0.004 & 0.068 & 0.274 & 0.495 & 0.575 \\
\hline Per. No qualifications & -0.130 & -0.055 & 0.170 & 0.407 & 0.492 \\
\hline Pop. Density & -0.723 & -0.619 & -0.347 & -0.098 & -0.021 \\
\hline Pre 2010 PV capacity & 0.193 & 0.285 & 0.602 & 0.959 & 1.091 \\
\hline Solar Irradiation & -0.110 & -0.070 & 0.051 & 0.173 & 0.215 \\
\hline Per. HH waste recycled & -0.390 & -0.319 & -0.118 & 0.076 & 0.137 \\
\hline
\end{tabular}

Lower 1\% Lower 5\% Mean Upper 95\% Upper 99\%
Rho
$0.219 \quad 0.350$
0.477

R-bar

0.493 


\section{References}

Balcombe, P., Rigby, D., and Azapagic, A. (2013). Motivations and barriers associated with adopting microgeneration energy technologies in the UK. Renewable and Sustainable Energy Reviews, 22:655-666.

Baskaran, R., Managi, S., and Bendig, M. (2013). A public perspective on the adoption of microgeneration technologies in New Zealand: A multivariate probit approach. Energy Policy, 58:177-188.

Bergman, N. and Jardine, C. (2009). Power from the people: domestic microgeneration and the low carbon buildings programme. Environmental Change Institute, University of Oxford.

Bollinger, B. and Gillingham, K. (2012). Peer effects in the diffusion of solar photovoltaic panels. Marketing Science, 31(6):900-912.

Campoccia, A., Dusonchet, L., Telaretti, E., and Zizzo, G. (2014). An analysis of feedin tariffs for solar pv in six representative countries of the european union. Solar Energy, 107:530-542.

Cherrington, R., Goodship, V., Longfield, A., and Kirwan, K. (2013). The feed-in tariff in the UK: A case study focus on domestic photovoltaic systems. Renewable Energy, $50: 421-426$.

Department of Energy and Climate Change (2012). Identifying trends in the deployment of domestic solar PV under the feed-in tariff scheme. Technical report, Department of Energy and Climate Change.

Elhorst, J. P. (2014). Spatial econometrics: from cross-sectional data to spatial panels. Springer. 
Graziano, M. and Gillingham, K. (2014). Spatial patterns of solar photovoltaic system adoption: the influence of neighbors and the built environment. Journal of Economic Geography, page lbu036.

Hawkes, A., Staffell, I., Bergman, N., Brett, D., Jardine, C., and Brandon, N. (2011). A change of scale? Prospects for distributed energy resources. Energy 2050: Making the Transition to a Secure Low Carbon Energy System, pages 219-247.

LeSage, J. and Pace, R. K. (2009). Introduction to spatial econometrics. CRC press.

LeSage, J. P. (2014). What regional scientists need to know about spatial econometrics. Available at SSRN 2420725.

Muhammad-Sukki, F., Abu-Bakar, S. H., Munir, A. B., Yasin, S. H. M., Ramirez-Iniguez, R., McMeekin, S. G., Stewart, B. G., Sarmah, N., Mallick, T. K., Rahim, R. A., et al. (2014). Feed-in tariff for solar photovoltaic: The rise of japan. Renewable Energy, 68:636-643.

Muhammad-Sukki, F., Ramirez-Iniguez, R., Munir, A. B., Mohd Yasin, S. H., AbuBakar, S. H., McMeekin, S. G., and Stewart, B. G. (2013). Revised feed-in tariff for solar photovoltaic in the United Kingdom: A cloudy future ahead? Energy Policy, $52: 832-838$.

OFGEM (2013). Feed-in tariff annual report 2012-13. Technical report, OFGEM.

Richter, L.-L. (2013). Social effects in the diffusion of solar photovoltaic technology in the uk. Technical report, Faculty of Economics, University of Cambridge. 